\title{
Reagan's U-turn on acid rain seen as election strategy
}

Washington

IN a politically motivated policy reversal, President Ronald Reagan has apparently agreed that the United States should freeze nitrogen-oxide emissions at 1987 levels, as proposed in international negotiations on a treaty designed to reduce acid rain. Word that Reagan supported the decision to adopt the freeze, reached at a meeting of Cabinet members involved in domestic policy, emerged at the end of last week.

\section{Gorbachev rallies the Soviet academy}

\section{London}

THE leadership of the Soviet Academy of Sciences must reconsider its programmes for the development of fundamental research, Mr Gorbachev told the Central Committee of the Communist Party of the Soviet Union, during a plenary meeting on implementing the resolutions of the recent party conference. Perestroika (restructuring), Gorbachev said, is impossible without the "active assistance of science", and, the state bodies - in particular the USSR State Planning Committee and State Committee for Science and Technology - must therefore examine ways to improve radically the financial and equipment base of science. Structural and investment policy, he said, must be revised to ensure the creation of favourable conditions for the development of priority trends.

Many major scientific centres, Gorbachev continued, are satisfied to play the part of commentators and critics, and have not noticed that perestroika has advanced from the "rally stage" to the "profound transformation" of all spheres of Soviet life. The criticism was directed at social scientists, but will have been noted by those in other fields. Somewhat surprisingly, in his address to the central committee, Gorbachev made no reference to the "scientificproduction associations" which three years ago he advocated as a means to cutting through bureaucratic barriers and bringing science closer to production.

In spite of Gorbachev's urging, relatively few such associations have been established, and even fewer have proved successful. The latter, in fact, have turned out to be little more than a new label for the longstanding involvement of particular research institutes (such as the Paton Welding Institute of the Ukranian Academy of Sciences) with local industry. The rest, as far as can be judged from the somewhat circumspect comments of the scientists involved, have not so much broken through the bureaucracy but simply added another layer to it.
The United States is one of the biggest contributors to global levels of nitrogen oxides, but the Reagan administration has been reluctant to acknowledge the role of nitrogen oxides and sulphur dioxides in acid rain, and to yield to international pressures to institute emission controls. The United States abstained from signing a protocol to limit sulphur-dioxide emissions which was agreed to by 16 nations including the Soviet Union in 1985, and the US failure to limit emissions linked to acid rain in Canada has been a major sticking point in relations between the United States and Canada. Reagan's agreement to the freeze on nitrogen-oxide emissions is being seen as an election-year attempt to bolster the Republican stance on environmental issues.

The current protocol stems from a United Nations-sponsored meeting held in Geneva in April of the signatories to the 1979 Convention on long-range transboundary air pollution. The convention, sponsored by the Economic Commission for Europe, involved 34 nations which agreed "gradually to reduce and prevent air pollution, including long-range transboundary air pollution".

Discussions at the April meeting boiled down to a dispute between the United States and Canada over the "transboundary flow" of nitrogen oxides which are produced in the United States and blow over the Canadian border. A clause specifically restricting transboundary flows to 1987 levels was introduced by the Canadians to counter an amendemt submitted by the United States that would set the freeze levels at those of 1987 or "any previous year."

Because US emissions generally have been declining over the past ten years, US negotiations sought some "credit" for past cutbacks while retaining some breathing room should emissions rise. US officials have repeatedly said that it is impossible to determine what proportion of domestic emissions are transported across the border, so by setting transboundary flows at 1987 levels, the Canadians effectively forced the United States into freezing emissions at those levels.

Canada has already frozen its nitrogen oxide emissions, but nitrogen oxides primarily produced by automobile emissions - are only a part of the acid rain story. Sulphur dioxide, almost all of it produced by coal-fired electricity generating stations, represents a far more intractible problem. The Reagan administration has put its faith into clean-coal technologies which will not mature until the next century.

The United States and Canada are
SERC support for materials research

London

THE Science and Engineering Research Council (SERC) last week set up a materials commission to coordinate research and improve links with industry. But the chairman of the commission, Professor Colin Humphreys of the University of Liverpool, says that an increase in funding for materials research is vital if Britain is to keep up with the world leaders in this field.

Humphreys says that funding has not increased in recent years, except in superconductivity research. And as other countries, particularly Japan and the United States, intensify their efforts, Britain is "in grave danger of falling behind". The commission takes on the role and funds previously assigned to the engineering and science boards and will administer a grants budget of $£ 15$ million. An additional $£ 2.7$ million from SERC will go towards setting up a new interdisciplinary research centre.

Professor Bill Mitchell, chairman of SERC, says that the council's support of materials research has been very fragmented and the new interdisciplinary commission will lead to a more integrated approach. It will have responsibility for research from synthesis of materials to prototype devices and demonstrator projects, and will respond to both "market pull and science push", says Humphreys.

The commission will comprise four new committees: in ceramics and inorganic materials; polymers and polymer composites; metals and metallurgy; and semiconductors, plus three existing committees for molecular electronics, superconductivity and medical engineering. On each committee there will be both academics and industrialists. Assessors from government departments will sit on the commission as a first step towards forming national materials-research priorities.

This new initiative indicates the high priority SERC is giving to materials research. "Materials underpins a wide range of wealth-creating technologies", says Mitchell. Some new materials on the horizon are sieves which are specific to particular molecules, ceramic materials which are superconducting at room temperatures and can carry critical currents and alloys with shape memories. Christine McGourty

expected to work out their differences before 31 October, which is the date the treaty will be signed in Sofia, Bulgaria. The treaty enters into force 90 days after it has been signed and ratified by all parties involved, and it stipulates that six months later negotiations should begin on "real reductions" to reduce emissions of nitrogen oxides below the freeze levels, which must be accomplished no later than 1996. 